\title{
Fieldwork protocol as a safety inventory tool in public places
}

\section{Vania Ceccato}

To cite this article: Vania Ceccato (2019): Fieldwork protocol as a safety inventory tool in public places, Criminal Justice Studies

To link to this article: https://doi.org/10.1080/09589236.2019.1601367

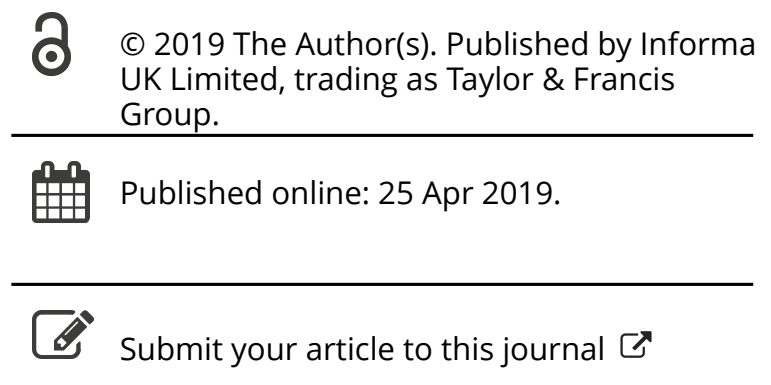

View Crossmark data $\nearrow$ 


\title{
Fieldwork protocol as a safety inventory tool in public places
}

\author{
Vania Ceccato \\ Department of Urban Planning and Built Environment, KTH Royal Institute of Technology, Stockholm, \\ Sweden
}

\begin{abstract}
This study reports on experiences using fieldwork protocols (FPs) in guiding the inventory of safety conditions in public places. Relying on theories of environmental criminology, situational crime prevention, and crime prevention through environmental design (CPTED), FPs are used to collect data on-site for three different types of public places: subway stations, shopping centers and parks. The fieldwork data are compared with other data sources and mapped using geographical information system (GIS) technology or building information modeling (BIM). Based on criteria of validity, reliability, and generalizability of evidence collected on-site, the study shows that FPs are better suited for environments that follow some uniform structure (subway stations) than other types of public places (urban parks). The article concludes with lessons for using FPs in guiding data collection for safety inventories and recommendations for future research.
\end{abstract}

\section{KEYWORDS}

Inspection; criminology; urban planning; qualitative research; validity; reliability; generalizability; BIM (Building Information Modelling); GIS (Geographical Infromation System)

\section{Introduction}

There is no novelty in stating that crime and fear of crime vary over time and space. To tackle problems of safety, researchers have long been developing tools in an attempt to capture the situational conditions that could lead to crime and/or trigger fear of crime. Some researchers have focused on capturing the quantitative character of the urban landscape and how that affects crime levels and/or fear (Ceccato, Haining, \& Signoretta, 2002; de Melo, Matias, \& Andresen, 2015; Weisburd, Morris, \& Groff, 2009). Others have devoted attention to finding ways of qualitatively assessing links between safety and features of the urban landscape (Armitage, 2013; Bamzar, 2019; Cozens, Saville, \& Hillier, 2005; Ekblom, 2019; Grönlund, 2012). Among these quantitative and qualitative approaches, fieldwork protocols (FPs) stand out as a popular tool for data collection. Creswell (2013, p. 168) defines FP as 'a predesigned form used to record information collected during an observation or interview.' Despite the vast use of FP in other research fields (e.g. Creswell, 2013) and also in criminology, there is a lack of studies assessing their potentialities to collect in-depth data.

The aim of this study is to report on experiences using FPs in guiding the inventory of safety conditions in public places based on environmental criminology theories and approaches. By using validity, reliability, and generalizability criteria, we assess how well 
FPs work for inspecting and collecting data through observation in subway stations, parks, and shopping centers. We submit that a well-designed FP enhances the quality of the data obtained on-site, which is fundamental for further analysis, either qualitative or quantitative. Principles of environmental criminology such as situational crime prevention and crime prevention through environmental design (CPTED) and routine activity work as a theoretical reference in the elaboration of these protocols.

The novelty of this article is that the evaluation of FPs done here combines interdisciplinary knowledge of architecture, urban planning, and environmental criminology. The article is also novel because it systematizes robust evidence in a methodological comparison of studies applied to public places of the same municipality (Stockholm, Sweden) and one in a northern European capital city (Vilnius, Lithuania), stretching over a period of more than 10 years.

The article starts with a discussion of the main environmental criminology theories that underlie the search for safety clues in the physical environment of the city. Fieldwork protocols are evaluated using principles of validity, reliability, and generalizability. The current study is framed later with a presentation of the study areas, methodology, and results. Conclusions and recommendations are finally presented, followed by some relevant background materials presented in the Appendix.

\section{Theoretical background}

\section{Safety in public places}

A public place can take a variety of forms and shapes. It can be a public park, open for all, a station, where many people pass by but may be restricted at certain hours of the day, or a hermetic shopping center that is public but not publicly owned, which means that not all parts are accessible by all. Social interactions and their results in these public places, such as being a victim of crime, are affected by differences in accessibility to these environments both temporally and spatially (Brantingham \& Brantingham, 1995; Felson, 2002; Rhodes \& Conly, 1981). This constitutes a reason for reflecting about the concept of public place. Public place can be defined as a space legally open and accessible to all without permission of anyone else, like a common (Németh, 2012). Most public places are conditionally free because actions allowed in these spaces fall under the laws of the locality in which these spaces are located.

Public place is more than an accessible place. It may bear a morality, which defines which behaviors are welcome, allowed, wanted, or enforced (Ceccato, 2016). Crime is dependent on a place's morality. The moral norms and the efficacy of their enforcement largely 'depend on what kinds of activities take place within them and what kinds of people tend to be present, both of which are likely to vary by time of day, week and/ or year' (Wikström \& Treiber, 2017, p. 82). The routine activity approach establishes that crime only occurs where and when the 'basic conditions' for crime are present (Cohen \& Felson, 1979) and only when a crime-prone person spends enough time in a criminogenic setting (Wikström, Mann, \& Hardie, 2018). A public place 'may become criminogenic when their activities and users encourage (or do not discourage) behavioral norms that conflict with the law, and/or they are ineffective at enforcing the law' (Wikström \& Treiber, 2017, p. 82). This criminogenic setting depends on how its 
microenvironments are designed, how it is used through the day by residents and visitors, and how well it is interlinked to the rest of the neighborhood and city.

\section{Urban environments and crime prevention through environmental design}

The type of building, its function and architectural design influence what occurs in the building, including in places surrounding it. According to situational crime theory (Clarke, 1983, 1997), this implies that environments can be planned following principles that reduce the opportunities for crime. Situational crime theory focuses on opportunityreducing processes that are aimed at particular forms of crime; entail the management, creation or manipulation of the immediate environment in an organized and permanent manner as possible; and result in crime being more difficult and risky or less rewarding and justifiable (Clarke, 1997). In an environment, this can be done by stimulating surveillance, fostering territoriality, and reducing areas of conflict by controlling access and improving overall perceived safety (Armitage, 2013; Cozens et al., 2005; Ekblom, 2011, 2019; Iqbal \& Ceccato, 2016; Jeffery, 1977; Newman, 1972; Saville, 2013). These principles underlie what is called crime prevention through environmental design (CPTED). CPTED is defined by Crowe (2000, p. 46) as the proper design and effective use of the built environment which can lead to a reduction in the fear of crime and the incidence of crime, and to an improvement in the quality of life.' The most traditional principles of CPTED are natural surveillance, access control, territorial reinforcement, and space management, but since the 1960s other principles (Jacobs, 1961; Newman, 1972; Reynald \& Elffers, 2009) have been incorporated to include the social dimensions of neighborhoods (Armitage, 2013; Cozens et al., 2005; Saville, 2013; Saville $\&$ Clear, 2000). The international literature has shown evidence that incorporating some of these principles of CPTED can help to create a safe and secure environment that encourages social interaction, promoting safety (for a review, see Cozens \& Love, 2015).

According to Ceccato, Falk, Parsanezhad, and Tarandi (2018), most CPTED interventions have been implemented together with other situational crime prevention techniques (Clarke, 2012) with reference to housing developments and neighborhoods (e.g. Armitage, 2013; Ceccato \& Bamzar, 2016; Clarke, 1983; DeKeseredy, Donnermeyer, \& Schwartz, 2009), transportation systems (Ceccato \& Paz, 2017; Loukaitou-Sideris, 2012), parks (Iqbal \& Ceccato, 2016), and commercial properties and shopping centers (Ceccato \& Tcacencu, 2018; Ceccato et al., 2018; Lindblom \& Kajalo, 2011).

Observers are the ones that collect the information through inspection of the environment. They have a central role implementing CPTED because they 'inspect' a particular environment, its design (internal and external), how it relates to the rest of the area, and how all these aspects affect crime opportunities and/or perceived safety. Although not free from criticism (Armitage, Monchuk and Rogerson 2011; Pain, 2000; Shaftoe \& Read, 2005; Sutton, Cherney, \& White, 2008) and showing contradictory evidence (Cozens et al., 2005), CPTED is valuable. This approach aims at gaining a better understanding of the effect of micro-spaces on individual behavior, either as a potential target or an offender seeking opportunities.

The most widely known CPTED principle relies on the notion of natural surveillance, which can be implemented in many ways. Open lines of sight in parks by guardians, handlers, and park managers can help to enhance natural surveillance (Felson, 1995), as 
can the implementation of closed-circuit television (CCTV). Another important dimension refers to territoriality and indicates how the physical design can develop a sense of ownership in specific areas (Reynald \& Elffers, 2009). Saville (2013) states that sense of ownership can help to create the idea of shared standards among different user groups (including gender perspective and people with special needs). Access control refers to property control using barriers, enclosures, and entry portals as well as pedestrianfriendly urban streetscapes or the installation of safety information signs through wireless network transmissions (audio/video) in smart cities. This can be combined with activity support that encourages interactions between residents and other users, thereby discouraging crime. Target hardening is about how the design of a space can make it difficult for people to steal or damage private and/or public property. Image of the place/ maintenance informs how pleasant esthetics keep potential criminals away because wellkept environments show that people are in control of the area. These principles have been called in the north American literature, the first generation of CPTED. According to Saville (2018), the second-generation CPTED includes principles that attempt to combine place's physical features with the social dimension of the environment and promote safety as part of sustainable development through social cohesion, connectivity, and community participation. There is also a third-generation CPTED, that relies on the potential of technology solutions to improve safety while adopting a green approach (Saville, 2018). In Scandinavia, CPTED principles have been implemented in the last three decades as a mix of first, second, and third generation in both new and existent residential areas much more as synonym of situational crime prevention than linked to the acronym CPTED.

In principle, CPTED can be implemented in FPs to inspect a particular feature of the environment in relation to safety, be that a park, a building, or a whole neighborhood. These protocols allow data to be gathered on-site after visual inspection or counting of items in the environment by the observer. Data are organized in an analog and/or digital form (through templates, structured questionnaires, checklists, diaries, or notes, for example). However, few studies have spent time assessing the adequacy of these protocols in criminology. Since there is no standard method for comparing the performance of these FPs as safety inventory tools, one way forward is to check whether and how the data coming from them satisfy some of the basic criteria of research, such as validity, reliability, and generalizability.

\section{Fieldwork protocols: validity, reliability, and generalizability}

Previous research has shown that fieldwork protocols are able to capture what is most important in the environment to explain why crime (or fear) happens at that particular place and time (Ceccato et al., 2018; Iqbal \& Ceccato, 2016). What should one expect from a safety inventory tool such as an FP?

First, it is expected that FPs can work effectively in collecting unbiased data (see issues of the validity and reliability criteria, for example). Second, FPs should provide stable measurements across items in the protocol (see issues of internal validity). Third, FPs can be created in a uniform way but can still be flexible and 'be translated' into different types of public places and contexts (see issues of criterion generalizability, for example). In summary, Table 1 offers a list of the basic conditions for protocols expected 
Table 1. Basic conditions of fieldwork protocols in safety inventory.

\begin{tabular}{|c|c|}
\hline $\begin{array}{l}\text { Fundamental } \\
\text { elements of FPs }\end{array}$ & Characterization of FPs for research \\
\hline $\begin{array}{l}\text { Validity - how successfully the fieldwork protocol has } \\
\text { actually achieved what it set out to do. }\end{array}$ & $\begin{array}{l}\text { Content validity means that if the protocol is created to } \\
\text { assess the presence of four CPTED principles (natural } \\
\text { surveillance, access control, territorial reinforcement, } \\
\text { and space management) in an area, then these } \\
\text { principles should be the backbone of the fieldwork } \\
\text { protocol. } \\
\text { Criterion validity is the extent to which records collected } \\
\text { using the protocol correlate (at a particular time or in } \\
\text { the feature) with other pre-existing records, as initially } \\
\text { hypothesized. }\end{array}$ \\
\hline $\begin{array}{l}\text { Reliability - the consistency of a measure in the } \\
\text { fieldwork protocol, over time, internally and across } \\
\text { observers. It depends on how measurable the } \\
\text { hypotheses/ } \\
\text { relationships are. }\end{array}$ & $\begin{array}{l}\text { Reliability over time is the extent to which data collected } \\
\text { are consistent over time, e.g. data collected at } \\
\text { rush hour compared with data recorded at the same } \\
\text { time of the day. } \\
\text { Internal consistency is dependent on the stability of the } \\
\text { measurements across items in the protocol, typically } \\
\text { a measure based on the correlations between different } \\
\text { items on the same test. } \\
\text { A fieldwork protocol should promote inter-observer } \\
\text { reliability, i.e. different observers should show a capacity } \\
\text { to identify 'the same reality' or similar evidence when } \\
\text { assessing CPTED principles in a particular place. }\end{array}$ \\
\hline $\begin{array}{l}\text { Generalizability - whether the fieldwork protocol (or } \\
\text { findings) can be applicable in other research contexts } \\
\text { or situations. }\end{array}$ & $\begin{array}{l}\text { Potential causal links between crime and types of } \\
\text { environment (obtained by fieldwork protocols) should } \\
\text { be tested and, whenever possible, applied to other } \\
\text { environments of the same type, to other contexts and } \\
\text { to other types of events in similar environments. }\end{array}$ \\
\hline
\end{tabular}
to other types of events in similar environments.

to be satisfied when designing protocols for data collection and/or on-site analysis for safety inventory.

Validity refers to the extent to which the FPs capture and measure the 'right' (expected) elements that need to be measured (Kelley, 1972). Content validity is the extent to which an FP includes all the constructs of interest, while criterion validity is the extent to which an observer's responses to variables in the protocol are correlated with other variables that one would expect them to be correlated with (not necessarily from the FPs). Examples of validity in data collection and on-site analysis using FPs are shown in Table 1.

Equally important when designing the FP is to consider the reliability of the tool which, according to Leung (2015), refers to exact replicability of the processes and the results coming from the protocols. This assumes that the use of FPs can be repeated (in different points in time or space) and/or that two or more observers can reach similar interpretations of 'a reality' by using the same questions, categories, and procedures. Measurements and observations on-site are expected to be accurate and consistent across places and across observers. In order to ensure that, time must be dedicated to thorough planning of the fieldwork, data-gathering procedures, sampling size of observers and on-site techniques. Table 1 shows that reliability can be assessed in three ways: across time, across items, and across different observers.

If one is interested in using FPs in other contexts or other situations, then one should be checking the generalizability of the data and analysis on-site. In the case of safety inventories, testing generalizability is a challenge and, sometimes, not even desirable, 
because case studies are often bound to a single framework applied to one or more phenomena (e.g. sexual harassment) in a certain public place (e.g. a park), in a particular context (e.g. city center), hence generalizability of qualitative research findings is usually not a required attribute of quality. However, as demand for knowledge synthesis from qualitative research has grown, evaluation of generalizability has lately increased via qualitative meta-synthesis, by summarizing qualitative findings from disparate studies into a single framework, so that the findings can be used more often in practice and policy (Finfgeld-Connett, 2010; Leung, 2015).

Drawing from the current body of knowledge, we submit that the performance of FPs can be compared using case studies as it is going to be reported in this study.

\section{The current study}

\section{Study areas}

Fieldwork protocols (FPs) are used for data collection in three different types of public place: subway stations, parks, and shopping centers in Sweden's capital, Stockholm, and a park in the capital of Lithuania, Vilnius. The municipality of Stockholm (Stockholms stad) has a population of 960,031 inhabitants (2019), spread over 188 square kilometers, the largest in Sweden and in Scandinavia. As a municipality, the City of Stockholm is subdivided into district councils or boroughs, which carry the responsibility for primary schools and social, leisure, and cultural services within their respective areas. The implementation of CPTED principles started voluntarily in the late 1990s in Sweden. It was not until 2005 that the National Housing Board incorporated some CPTED principles in its policies (Grönlund, 2012). However, even today these principles are not mandatory in new housing developments or commercial buildings.

Stockholm's subway system is the 20th longest in the world, with a track length of 110 kilometers divided among three lines: green, red, and blue. The Central Station ( $T$-Centralen subway station) has the largest number of passengers per day, in a system composed of 100 stations, of which 47 are underground and 53 above ground (Ceccato, 2013). The shopping center used here as study area is a mall located adjacent to a metro line on the outskirts of Stockholm, in an area with relatively high crime levels. When built in the late 1970s, and even when later refurbished, the shopping center was not planned with CPTED principles in mind. Finally, evidence from parks is based on two case studies, one from Stockholm, Sweden, and the other from Vilnius, Lithuania. For details about the parks, see Ceccato and Lukyte (2011) and lqbal and Ceccato (2016).

\section{Data and methods}

Figure 1 illustrates data collection process and the four steps taken to assess FPs as tools for inspecting the physical and social environment of three types of public place. In this article, we concentrate on reporting activities under step 4. Step 1 describes the data collection used in study cases. Note that each case study was developed independently over a course of about 10 years. As step 1 illustrates, rather than adopting a single perspective, this research makes use of both qualitative and quantitative perspectives a mixed method approach - to allow a better understanding of the problems being 


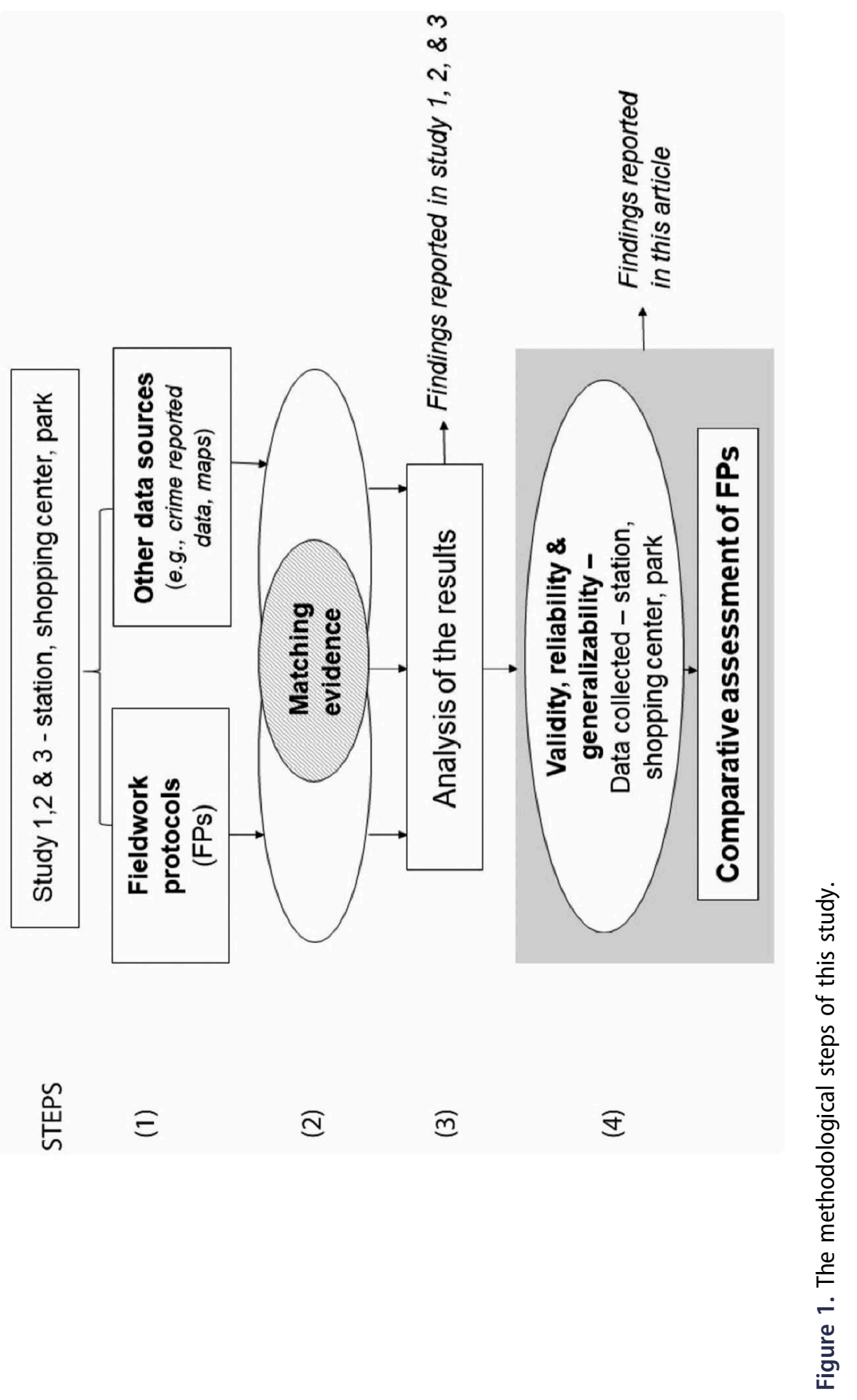


researched (Clark \& Creswell, 2011). This means we combined data from maps, crime police data, photographs and observations with FPs described in detail in each study. Step 2 describes the processes of combining data from different sources and finding common patterns as well as aspects and issues that showed different patterns when these different data sources were put together. In step 3, findings were reported in four different studies as described below.

\section{Steps 1, 2 and 3 - Data collection and analysis}

For the case study of the subway stations, FPs were composed of checklists, such as the one presented in Appendix, combined with photographs, and later analyzed with secondary data sources using georelational databases, spatial statistical techniques, and geographical information systems (GIS). Although the internal environments of subway stations follow some common standards (e.g. illumination, platform/lobby structures), they are not exactly the same, which can impact on the stations' vulnerability to crime and perception of safety. To capture these environmental differences, a systematic and detailed inspection using FPs was used in all stations of the subway system. The FPs were detailed checklists implemented in spreadsheets divided into five different parts following the station's parts: the platform, the transition area, the lobby, the exits, and the immediate surrounding area (see Appendix). The station platform is where the trains arrive and passengers wait. The transition area is the area between the platform and the gates/ticket booths and commonly includes stairs and elevators to the platform. The lobby is the area between the gates/ticket booths and the exits or tunnels. The exits are areas limited to entering the lobby area, either directly from the street or via a tunnel. The surroundings include the immediate surroundings around each exit, i.e. the field of view from a station exit (Figure 2).

In each part, different aspects of the station's environment were collected and measured. For instance, visibility, surveillance capacity, crowdedness, and smell in the elevators were assessed using a low-medium-high scale. Visibility was a function of how much one could see from the location, thereby giving an inside-outside perspective, 'you' in relation to others, while surveillance was defined as how well others can see 'you,' providing the outside-inside perspective. For instance, for all stations the visibility and possibility of surveillance were assessed; any dark places or vandalism was noted and registered using the protocols. Likewise, the presence of security cameras and guards, drunken people, overall crowdedness, and area-specific features such as types

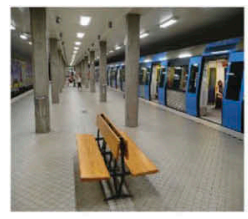

Platform

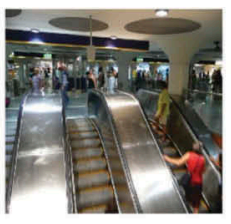

Transition

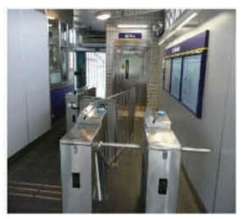

Hall

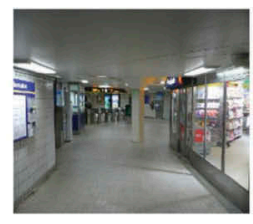

Exit/entrance

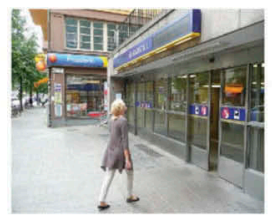

Immediate surroundings

Figure 2. The five sections of subway stations: platform, transition, hall, exit/entrance and immediate surroundings. Photographs by Adriaan C. Uittenbogaard, Roya Bamzar and Vania Ceccato, 20112018. 
of entrance gates, cash machines, and types of wall were noted. For instance, crowdedness was classified as low for 0-5 people, medium for 6-10 people, and high for more than 11 people in each section of the station. Unlike pure quantitative research which deals primarily with numerical data and quantifiable interpretations of reality, this type of data collection and on-site analysis also involves qualitative research dealing with non-numerical information and its phenomenological interpretation, which directly relates to the human senses and subjectivity (Leung, 2015), in other words, the way we use and perceive the environment. Thus, smell was subjectively categorized (as low, medium or high) by its strength from, for instance, urine. The features that characterize the stations' surroundings (e.g. the presence of shops, bus stops, parking, ATMs, bars, motorways, parks, litter, drunken people) were checked using these FPs, including in which type of immediate surrounding the station was embedded, such as residential, commercial, or mixed. All subway stations were inspected on a weekday, between $10 \mathrm{am}$ and 4 pm, thus avoiding atypical hours (peak hours and busy weekends) in the summertime. Using crime and perceived safety as dependent variables, we used the data collected at the stations in the FPs as covariates in regression models. (Details see Ceccato \& Uittenbogaard, 2014; Ceccato, Uittenbogaard, \& Bamzar, 2013)

For the case study of the shopping center, on-site data collection was performed using checklists. Results were later compared with secondary data and complemented with questions from a digital safety survey (Google forms) and photographs. Both results were later mapped using a 3-D model implemented in building information modeling (BIM). Drawing on CPTED principles, a conceptual framework for assessing spaces and times that are criminologically relevant to crime and perceived safety was proposed. How much visitors are exposed to crime depends on their location at a particular time in the mall as well as internal and external features such as good lighting, design and position of doors, windows and staircases, and entrances. The analysis was carried out looking at functional spaces, those spaces which have a defined function in the shopping mall, such as stores, restaurants, banks or toilets. Open public spaces in a shopping mall have a key role in terms of safety, as they are settings of convergence at all times. Shopping centers also have transitional areas, such as corridors, stairs, and paths. Length and width, location, types of materials, enclosure and design all affect how safe these transitional areas are. The entrances/exits carry the identity of the shopping center. They can be of many types, for pedestrians and for cars, giving access to the parking lot, for example. In any case, wellfunctioning entrances allow the flow of people (or cars), under normal and emergency conditions. The shopping center's immediate surroundings are also an important criminogenic factor for what happens inside the mall. Data were collected through fieldwork inspection using protocols in a spreadsheet completed during a series of visits to the shopping center in particular environments most targeted by crime and incidents of public disturbance. Spots showing high crime areas were inspected using FPs. Fieldwork information was later combined with reports of occurrences of crime (secondary data) over a period of 17 months (from January 2015 to May 2016) and a perceived safety survey applied using mobile telephones and photographs of the shopping center (for details, Kajalo and Lindblom, 2010); Ceccato et al., 2018; Ceccato, 2018). The crime records constituted by police recorded data collected from three sets of coordinates covering the location of the shopping center, and cartographic maps were later digitalized using either AutoCad or GIS. Figure 3 illustrates the results of the secondary data mapped using BIM, which served as 


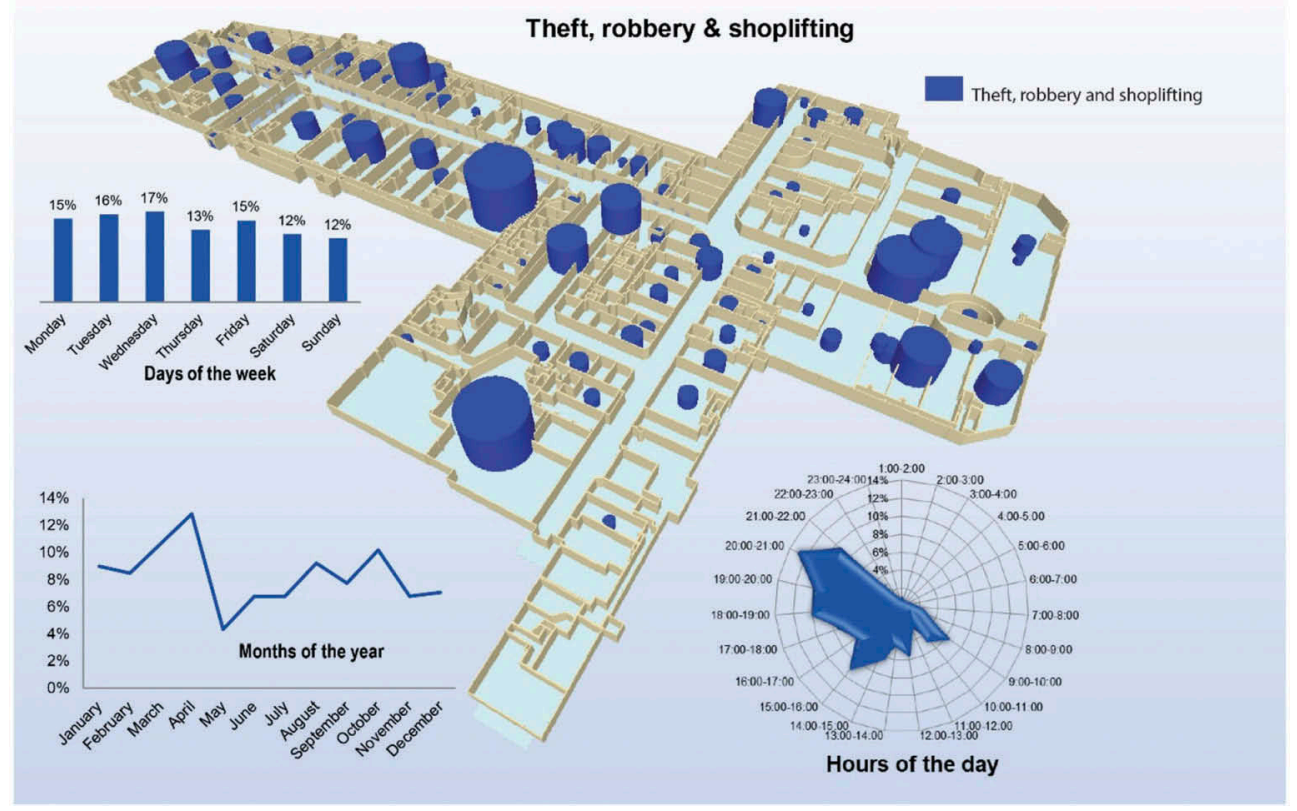

Figure 3. Secondary data mapped using building information modeling as background information for working with fieldwork protocols in shopping centers.

background information for defining fieldwork strategies using the protocols. For instance, using these BIM (Building Information Modelling) maps, we were able to visualize the spots with major safety problems in space and time.

For the case study of the parks, FPs were used on a 'safety walk' (Vilnius case), and a park inspection (case studies in Stockholm) allowing the visual inspection of the park through observations. In Vilnius, the safety walk (or audit) is an inventory of the features of an area (or a park) that affect individuals' perceptions of safety. Safety walks help individuals to look at a space that feels unsafe and determine why it feels unsafe, applying CPTED principles, routine activity theory and situational crime prevention as guidance. Safety walks can be used to demonstrate how daily fears translate into concerns about the physical environment, which is useful information for planners (Ceccato \& Hansson, 2013). During the walk, participants decided when and where to stop if they felt they had something to tell. Twenty-five individuals participated in the safety walk, which took about one-and-a-half hours on a weekday in the spring of 2011.

The protocol (Figure 4) allowed for each participant to indicate wherein the park problems occur, descriptions of the problems, and some basic participant information, such as age and gender. In the example of the park by lqbal and Ceccato (2016), FPs were also used as a safety inventory tool with safety walks in combination with maps of police-recorded data as well as safety questionnaires as alternative sources of information. Observers using FPs in the park varied their observations over time in an effort to collect data that reflect the park at all times (Details see Ceccato \& Hanson, 2013; lqbal \& Ceccato, 2016). 


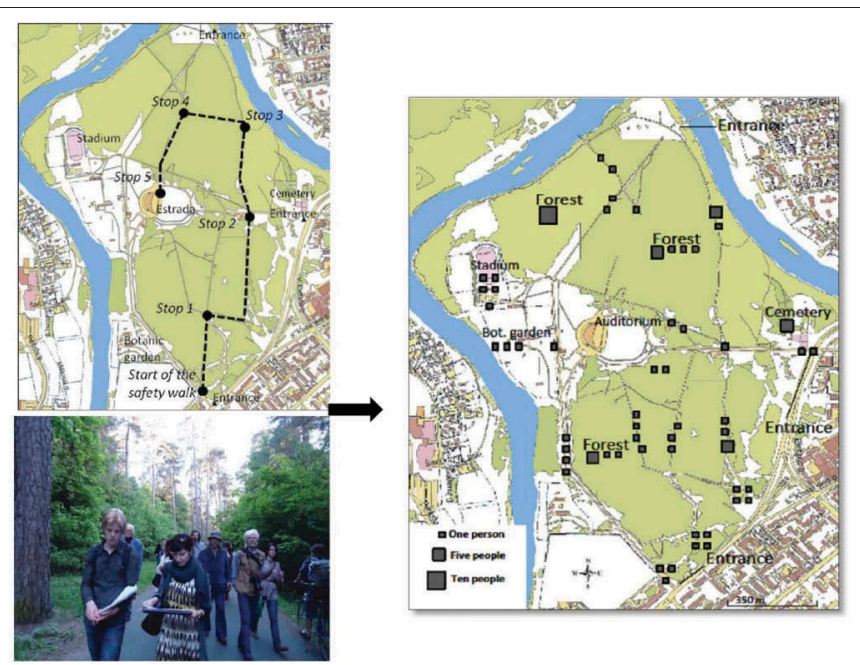

Use of protocols in safety walks

\section{Preparation}

Invite participants (strive as far as possible to gather people of different backgrounds and interests) that reflect the people who reside and/or work in that particular place. Define time \& place for a preparation meeting.

\section{Meeting the participants}

Explain the aim of the walk. Show how the area to be visited and how they may be split into groups to cover the area. Produce maps of the area where the walk will be held. Show the protocol to be used and how it can be filled in. One aim of the walk is to strengthen the feeling of the area. Discuss with participants the history of the park and changes that have occurred. Encourage participants to bring mobile phones to record the safety walk by taking photographs and recording comments along the way.

\section{Introduction to the walk \& protocol}

Meet at the designated place and time. Propose a route to participants and immediate actions to participants (what to see, what to make notes about, as previously discussed in

2). The leader can plan 1-2 locations as examples and help participants fill in the protocols.

\section{Actions along the walk}

Ask participants to find places/times that tend to concentrate visitors and whether they can be improved. Ask them to express how it feels (or how they imagine it feels) to be alone at different locations at different times of the day, as well as in different seasons. Stop along the route and keep the conversation open so everyone gets their say. Make sure they keep their eyes open for things that pop up along the way. What does the entrance look like? Is better illumination needed? Are there environmental features that create barriers to access for visitors? Highlight that different groups think of different things when they think of "safety" (be prepared for conflicting views).

\section{Actions along the walk}

Compile all completed protocols from the participants into a single database. Summarize the experiences and identify problematic locations and any meaningful differences and points of conflict between participants' views. Inform the next steps in the study (using data collected on-site). Provide your contact details to participants so they can get in touch and add information or further thoughts and can get feedback from the fieldwork organizer.

Figure 4. Fieldwork protocol used in a safety walk through Vingis Park, Vilnius, Lithuania. The route of the safety walk (upper-left corner), participants, and the output map with identification of places described as unsafe. Based on Ceccato and Hansson (2013) 


\section{Step 4 - Comparative assessment of FPs and scores}

Step 4 illustrates how FPs were assessed based on how well FPs performed in 'inspecting and collecting data through observation' in terms of validity, reliability and generalizability. Since different scales of analysis were used in each study, 'the original data' were not appropriate to indicate how well FPs performed as a data collection/inspection tool. In order to be able to compare the data collected from these studies, 'data' were transformed into 'a qualitative assessment' and 'scores' varying from high, to medium and low in terms of validity, reliability and generalizability, as illustrated in the next section. For example, FPs from parks got much more discrepant evaluations from observers than stations did. This means that stations got a higher score in generalizability, for example, than FPs applied to parks did, assuming constant potential differences in the profile of inspectors, such as age and gender.

The final comparative assessment (Step 4) was systematically performed for all three public places using three subjective scores - high, medium and low - linked to the criteria of validity, reliability, and generalizability of FPs. This means that the public place that imposed 'less of a challenge' for FPs as a data collection tool in terms of validity, reliability, and generalizability earned the highest score (high). Conversely, FPs from parks got much more discrepant evaluations in terms of validity, reliability, and generalizability than FPs applied to stations did, so FPs from parks scored medium/low in all assessment criteria. If moderate challenges in the application of an FP were found during the fieldwork in a particular environment, a score of medium was associated with the FP. For example, the internal reliability was medium/low for parks (because of heterogeneous differences of the park environments, size and location) but high for stations (the standardization of the stations facilitates internal reliability).

\section{Results}

\section{Reporting findings by type of public place}

\section{Subway stations}

Findings showed that safety conditions in transport nodes depend on "multi-scale conditions that act at various levels in an urban environment. The analysis involved an evaluation of the relationship between events of crime and environmental attributes of subway stations and surrounding areas collected using FPs (an example is illustrated in Appendix), which were later analyzed using regression models and GIS. These conditions are determined by the environmental attributes of the station, the characteristics of the immediate environment, the type of neighborhood in which the station is located, and the relative position of both the station and the neighborhood in the city (Ceccato, 2013). The temporal dimension (peak/off-peak, day of the week, and season) was considered an important dimension of the study. The results are summarized in three articles (Ceccato, 2013; Ceccato \& Uittenbogaard, 2014; Ceccato et al., 2013) that independently report the importance of FP as a data collection tool. They highlight some of the challenges of validity (content and criterion), in other words, the adequacy of CPTED principles applied to transit environments as well as among the different measures. 


\section{Shopping centers}

The study showed that violent and property crimes and acts of public disturbance in shopping environments are spatially and temporally clustered in three-dimensional space. In order to assess the environments where crime is most concentrated, a systematic and detailed inspection of the crime locations in the shopping center (including photographic documentation) using FPs was conducted together with an assessment of the surrounding area of the shopping center.

Results from the visualization combined with the fieldwork inspection provided the basis for making suggestions for improvement of the most targeted settings and/or areas in the shopping center. The results are illustrated in Table 2. This analysis was also combined with perception of safety by visitors and published in two publications (Ceccato, 2018; Ceccato et al., 2018) reporting the adequacy and challenges of using FPs when different data sourses do not match each other (criterion validity) and when FPs are used in public places that are privately owned.

\section{Parks}

The inspection of these two parks brought out a range of issues often found in previous women's safety audits: broken lights, places where it is difficult to get one's bearings (lack of signs), bushes growing in places which would make individuals feel unsafe, graffiti, trash, dogs running around freely, slippery pavement in the winter, prohibited parking areas, and bikers riding on walking paths. These two studies indicate that the most important methodological challenge was to translate CPTED principles into features that could be identified in the parks using FPs to serve as an inventory tool to pinpoint safety problems. Features of territoriality, activity support and target hardening were visible, as was park maintenance. Also, the size of the park made it difficult to control the whole area, and in some places, the design made it permeable for cars. As expected, the problem of poor inter-observer reliability was much more evident in the safety survey in Vilnius park than in the Stockholm case study. However, FPs were regarded as useful tools of data collection and fieldwork analysis (Details see Ceccato \& Hanson, 2013; lqbal \& Ceccato, 2016). Some of the most important challenges are discussed in detail in the next section.

\section{Assessment of fieldwork protocols}

Table 3 summarizes how well FPs perform in terms of validity, reliability, and generalizability of the evidence captured by one or more observers in the environment of subway stations, shopping centers, and parks. By comparing the evidence from FPs among themselves as a safety inventory tool (stations, a shopping center, and parks) and with other data sources, one can assess how well this evidence can establish links with these environments. Below we provide a few examples.

Table 3 shows that when using FPs for all three types of public places it is easier for the observer (the one inspecting the environment) to ensure content validity (how successfully the FP has actually achieved what it set out to do by covering all dimensions under CPTED principles) than criterion validity (e.g. the extent to which observer measures are correlated with other, pre-captured measures). Example: High robbery rates are often validated against measures of poor surveillance or other environmental features of places that 
Table 2. Examples of places most in need of intervention along CPTED principles.
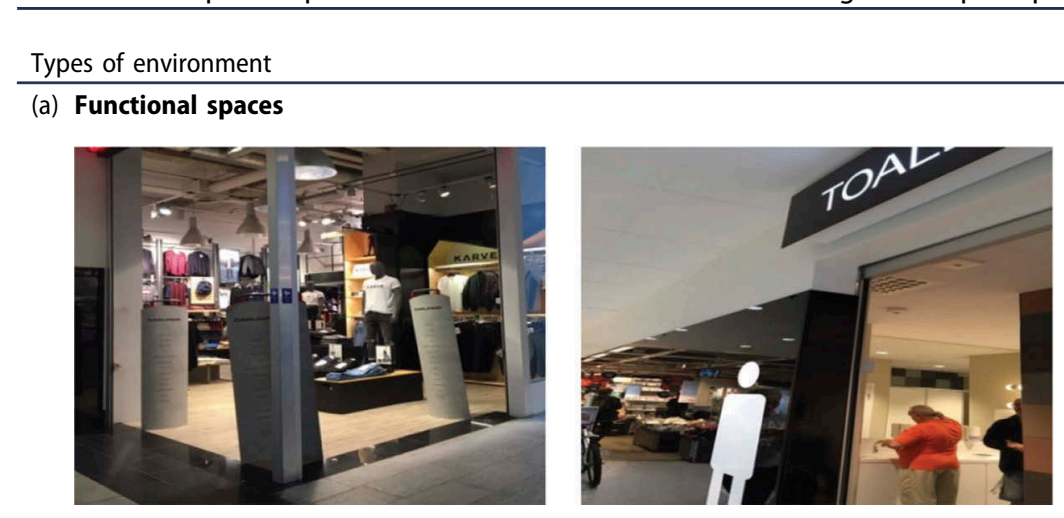

Main safety issues

*permeable

spaces

*poor

territoriality

markers

*lack of access

control

*easy escape

*unintended

use of

premises

(a)

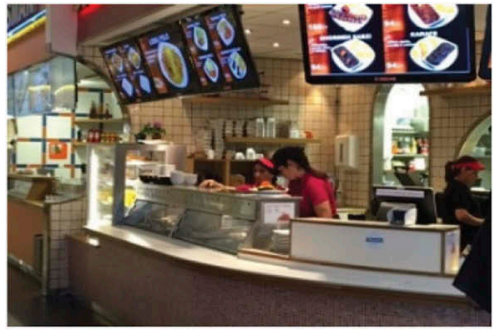

(a)

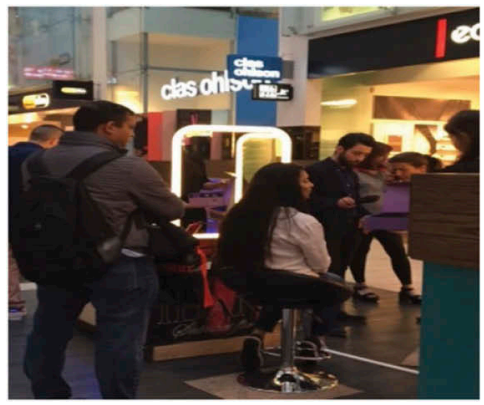

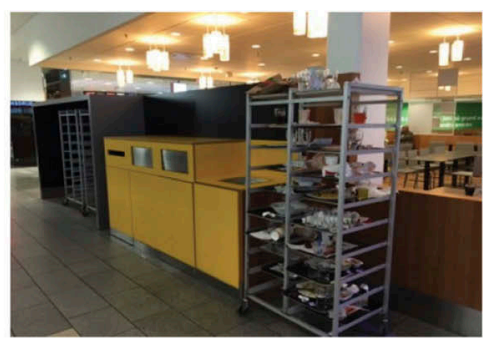

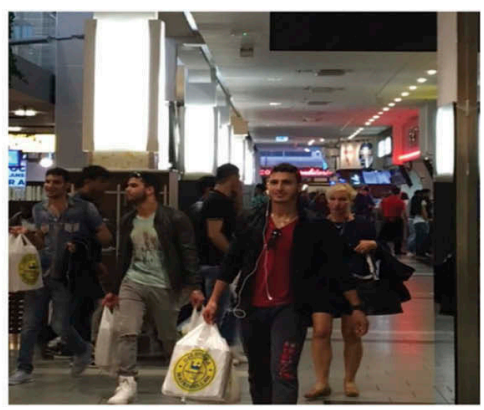

*poor natural surveillance (blocked view, hidden spots) *access control \& permeable spaces *image/poor management

*tight corridors *disruption by physical barriers * poor natural surveillance stalls affect visibility *products easy to steal (a) Entrances/Exits

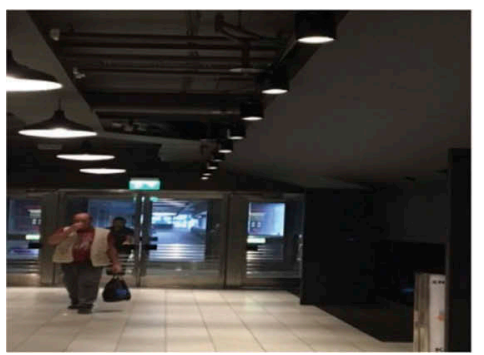

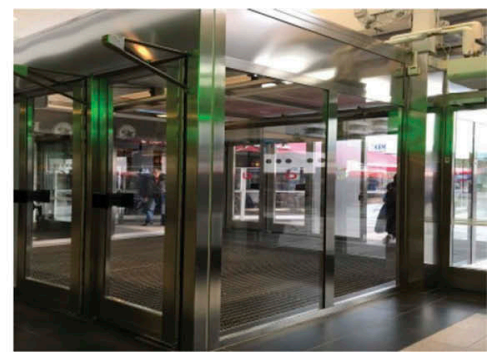

*illumination *easy escape *lack of access control 
Table 2. (Continued).

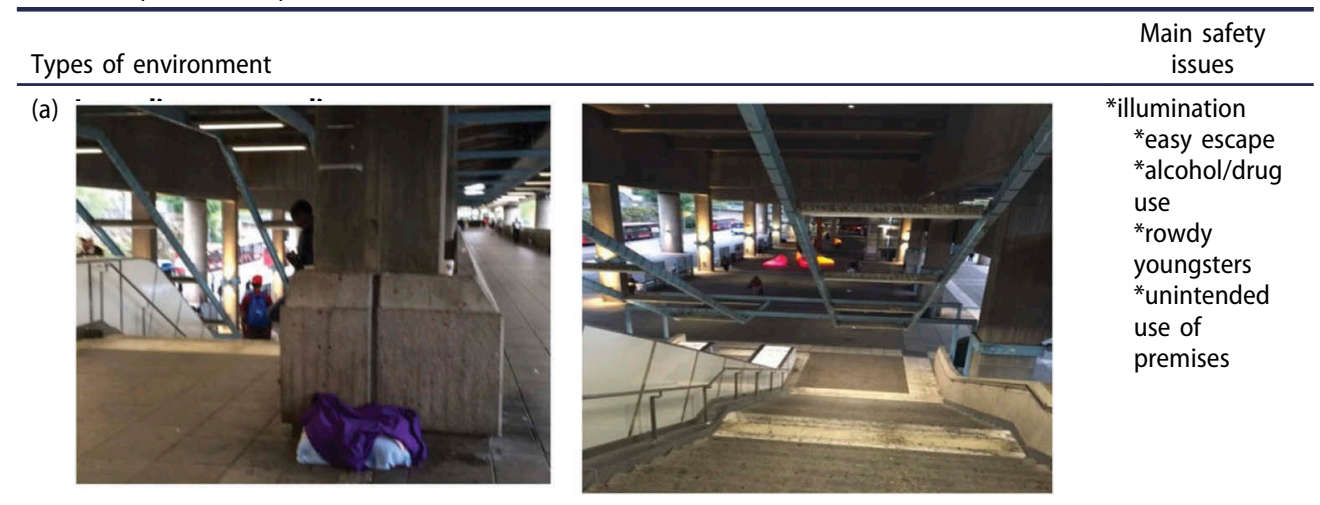

Source: Ceccato et al. (2018, p. 201).

promote anonymity (the criterion). Content validity is dependent on the theoretical preparedness and experience of the observer: how well they can transfer their knowledge into the protocol. The observer can ensure that by making sure that all dimensions of the FPs cover the theoretical principles that are being tested. Different types of public place pose challenges to the performance of FPs in terms of validity. They perform better in subway stations (albeit depending on the part of the station) than they do in shopping centers and parks. High validity is found, for instance, in built-up areas of the parks, but low validity in open, forested, or the most remote areas.

Reliability over time is the extent to which data collected are consistent over time, e.g. data collected at rush hour compared with data recorded at the same time of the day. Example: Noise levels in decibels at a subway station's platform at early rush hour should be similar to noise levels recorded on other days at about the same time. Concerning reliability of the measures over time, the protocol also scores higher in subway stations than in other environments. Open spaces, such as parks, impose the biggest challenge to the use of FPs, because they vary over time, even more so for a park (unpredicted flow of visitors) than for an indoor shopping mall (predicted flow of visitors).

Internal consistency is dependent on the stability of the measurements across items in the protocol, typically a measure based on the correlations between different items on the same test. In our case studies, we have seen examples when high scores of poorly maintained place correlated with high scores of 'poorly lighted,' broken lamps, damage illustrating a high score for internal consistency.

It is expected that an FP should promote inter-observer reliability, i.e. different observers should show a capacity to identify 'the same reality' or similar evidence when assessing CPTED principles in a particular place. This means that an experienced researcher identifies evidence of territoriality (e.g. detects the presence of a wall between private and public space) in a way similar to how a novice student would, guided by the same FP. This is because the use of FPs assumes that observers share a similar theoretical template to be able to identify similar 'things' in the environment that indicate a problem with safety, or 'environmental weakness' (Ekblom, 2011). 
Table 3. Validity, reliability, and generalizability of evidence from fieldwork protocols by type of environment.

\begin{tabular}{|c|c|c|c|c|}
\hline & \multicolumn{4}{|c|}{ Environmental features - safety inventory } \\
\hline & & Subway stations & Shopping center & Parks \\
\hline \multirow[t]{2}{*}{ Validity } & Content & $\begin{array}{l}\text { High - depends on the } \\
\text { parts of the station, e.g. } \\
\text { high validity in the } \\
\text { platform but low in } \\
\text { transition or surrounding } \\
\text { areas. CPTED theory fits } \\
\text { well for micro-spaces, but } \\
\text { not all elements of it. }\end{array}$ & $\begin{array}{l}\text { Medium - depends on the } \\
\text { parts and size of the } \\
\text { shopping center, e.g. } \\
\text { high validity in functional } \\
\text { spaces such as stores but } \\
\text { low in transition areas } \\
\text { and entrances. Theory - } \\
\text { as for subways. }\end{array}$ & $\begin{array}{l}\text { Medium/Low - not all } \\
\text { CPTED principles can be } \\
\text { tested in parks (e.g. } \\
\text { territoriality). Park size } \\
\text { and city location impose } \\
\text { limitations to fieldwork } \\
\text { protocols. High validity in } \\
\text { built-up areas of the park, } \\
\text { low in open areas. }\end{array}$ \\
\hline & Criterion & $\begin{array}{l}\text { Medium - factors collected } \\
\text { by the protocol do not } \\
\text { always automatically } \\
\text { indicate causal links with } \\
\text { pre-existent measures, } \\
\text { e.g. the evidence of } \\
\text { presence of CCTVs in } \\
\text { a station by the protocol } \\
\text { does not automatically } \\
\text { validate good levels of } \\
\text { surveillance at the station } \\
\text { at a particular time and/ } \\
\text { or in the future. }\end{array}$ & $\begin{array}{l}\text { Medium - fieldwork } \\
\text { protocols suggest that } \\
\text { high levels of luminance } \\
\text { in a store (or other } \\
\text { functional places) do not } \\
\text { automatically validate } \\
\text { good levels of } \\
\text { illumination or high } \\
\text { declared levels of } \\
\text { perceived safety, at } \\
\text { a particular time or in the } \\
\text { future (predictive } \\
\text { validity). }\end{array}$ & $\begin{array}{l}\text { Medium - as in stations } \\
\text { and shopping } \\
\text { environments, it is not } \\
\text { easy to ascertain the } \\
\text { extent to which } \\
\text { a measure is related to an } \\
\text { outcome using the } \\
\text { fieldwork protocol, } \\
\text { because causality also } \\
\text { depends on pre-existent } \\
\text { measures as well as the } \\
\text { knowledge and } \\
\text { experience of the } \\
\text { observer/researcher. }\end{array}$ \\
\hline \multirow[t]{3}{*}{ Reliability } & Time & $\begin{array}{l}\text { High/medium - based on } \\
\text { the assumption that the } \\
\text { use of fieldwork protocols } \\
\text { (with the same questions, } \\
\text { categories and } \\
\text { procedures) can be } \\
\text { repeated over time. It is } \\
\text { crucial to identify } \\
\text { beforehand temporal } \\
\text { patterns before } \\
\text { comparisons are made, } \\
\text { e.g. peak and off-peak } \\
\text { hours at subway. }\end{array}$ & $\begin{array}{l}\text { High/medium - fieldwork } \\
\text { protocols produce stable } \\
\text { and consistent results as } \\
\text { an inventory safety tool. } \\
\text { As in stations, knowledge } \\
\text { about potential temporal } \\
\text { variations of } \\
\text { a phenomenon in the } \\
\text { shopping center over } \\
\text { time is fundamental, such } \\
\text { as the number of visitors } \\
\text { to the center by hours of } \\
\text { the day, days of the week } \\
\text { and season. }\end{array}$ & $\begin{array}{l}\text { Medium/low - a park's } \\
\text { environment is bound to } \\
\text { change with daily, } \\
\text { weekly, and seasonal } \\
\text { variations (in particular in } \\
\text { contexts where winters } \\
\text { include cold } \\
\text { temperatures), which } \\
\text { limits the degree to } \\
\text { which fieldwork protocols } \\
\text { as an inventory safety } \\
\text { tool produce stable and } \\
\text { consistent results. }\end{array}$ \\
\hline & Internal & $\begin{array}{l}\text { High - fieldwork protocols } \\
\text { used in stations measure } \\
\text { whether several items } \\
\text { (that propose to measure } \\
\text { the same general } \\
\text { construct) produce } \\
\text { similar scores. }\end{array}$ & $\begin{array}{l}\text { High - as in stations, } \\
\text { standardized entrance } \\
\text { halls facilitate } \\
\text { comparisons between } \\
\text { different items (e.g. } \\
\text { indoor illumination) on } \\
\text { the same test using } \\
\text { dummy or numerical } \\
\text { scales. }\end{array}$ & $\begin{array}{l}\text { Medium/low - fieldwork } \\
\text { protocols might impose } \\
\text { limitations when used for } \\
\text { parks because of } \\
\text { heterogeneous } \\
\text { differences of the park } \\
\text { environments, size and } \\
\text { location. }\end{array}$ \\
\hline & Observer & $\begin{array}{l}\text { High - passengers at } \\
\text { particular times share } \\
\text { commonalities (they are } \\
\text { all in transit, going } \\
\text { somewhere), which } \\
\text { facilitates the use of } \\
\text { fieldwork protocols and } \\
\text { comparisons within and } \\
\text { between groups at } \\
\text { particular times. }\end{array}$ & $\begin{array}{l}\text { Medium - visitors to } \\
\text { a shopping center are far } \\
\text { from being } \\
\text { homogeneous, looking } \\
\text { for different products } \\
\text { and/or services. } \\
\text { Fieldwork protocols and } \\
\text { comparisons within and } \\
\text { between groups can be } \\
\text { facilitated by grading and } \\
\text { Likert scales but also by } \\
\text { photographs and notes } \\
\text { from different observers. }\end{array}$ & $\begin{array}{l}\text { Medium - as in shopping } \\
\text { centers, park visitors are } \\
\text { far from being } \\
\text { homogeneous (passing } \\
\text { through to school, sitting } \\
\text { on benches, drinking), } \\
\text { but they all share } \\
\text { a commonality: they are } \\
\text { spending time at the } \\
\text { park. Fieldwork protocols } \\
\text { allow for a variety of } \\
\text { different park users in } \\
\text { urban planning to } \\
\text { increase validity of the } \\
\text { tool. }\end{array}$ \\
\hline
\end{tabular}


Table 3. (Continued).

\begin{tabular}{|c|c|c|c|}
\hline & \multicolumn{3}{|c|}{ Environmental features - safety inventory } \\
\hline & Subway stations & Shopping center & Parks \\
\hline Generalizability & $\begin{array}{l}\text { High/medium - fieldwork protocols } \\
\text { using CPTED principles when } \\
\text { applied to stations can easily be } \\
\text { generalized throughout the transit } \\
\text { system, although differences in } \\
\text { contexts (inner city, end stations) } \\
\text { impose limitations to the degree of } \\
\text { generalization. }\end{array}$ & $\begin{array}{l}\text { Medium - potential causal } \\
\text { links between crime and } \\
\text { types of environments in } \\
\text { a shopping center } \\
\text { obtained using } \\
\text { a fieldwork protocol can } \\
\text { be generalizable to other } \\
\text { types of shopping } \\
\text { centers. However, } \\
\text { shopping centers vary } \\
\text { highly in size, complexity } \\
\text { of services, and location. }\end{array}$ & $\begin{array}{l}\text { Medium - as in shopping } \\
\text { centers, parks vary highly } \\
\text { in size and function } \\
\text { (urban forests, } \\
\text { neighborhood parks, } \\
\text { water parks) as well as } \\
\text { location, limiting the } \\
\text { generalizability of } \\
\text { findings coming from } \\
\text { fieldwork protocols, } \\
\text { either from inventory of } \\
\text { crime location and/or } \\
\text { perception of safety. }\end{array}$ \\
\hline
\end{tabular}

However, it is not always easy to impose this 'common template' from the start, since we may all come together with 'different cognitive templates' regardless how many years of experience as observers we have. This is well illustrated by Ekblom (2011) in his attempt to define 'territoriality' in CPTED. The author points out the difficulty of choosing indicators of territoriality in the field, between the 'real and obvious' hinders and 'the symbolic and subtle' barriers:

In practical terms (territoriality) is realized often through barriers both symbolic (such as signage or changes in road surface), and real (such as fences defining particular spaces). (Ekblom, 2011)

The difficulty of keeping a high inter-observer reliability can be remediated if observers are always well-trained based on the same visual cues before they set off for the fieldwork. From the example above, this means that observers should discuss thoroughly 'the visual cues and boundaries' of CPTED definitions before they go to fieldwork.

A high inter-observer reliability becomes a challenge when CPTED principles are imposed in different country/cultural contexts (Armitage, 2013; Ekblom, 2011). Ekblom (2011) suggests that the concepts and the practical definitions of territoriality - for instance, public, semi-public, and private space as suggested by Newman (1972) - are likely to be individually and culturally determined, particularly with regard to the balance of the individual versus the collective dimensions. The author states that 'territoriality also requires particular roles to be understood: owner, occupier, visitor, intruder and so forth' (Ekblom, 2011, p. 23).

We argue here that poor inter-observer reliability promoted by FPs (resulting, say, from observers varying widely on how they assess a particular reality) is not necessarily a limitation of the tool for practical purposes. This is because these differences in perceptions and opinions indicated by observers can be a desirable feature in participatory planning schemes, reflecting perhaps a more interdisciplinary take on a problem. 
Overall, when all these criteria were assessed together, FPs scored higher in transit environments than they did in those environments found in shopping centers or parks with regards to generalizability (Tables 3 and 4).

This means that conclusions about a station (drawn from the evidence in these protocols) can more easily be generalized throughout the transit system than it can be done for information collected for a shopping center or a park. The standardization of transit systems is the reason for this outcome. While 100 subway stations have some similar elements in their design, structure and size, shopping centers vary greatly, from a strip mall with a limited number of stores, to a large grouping of establishments with a number of eclectic services and functions, including sports, culture, and entertainment. In summary, Table 4 indicates that FPs applied to subway stations scored 'high' in all three aspects of evaluation (validity, reliability, and generalizability), while parks did not score 'high' in any of them.

\section{Discussion of the results}

Drawing from section 4.1, results show that safety inventories in subway stations, a shopping center, and parks indicate the adequacy of FPs as a tool for data collection through observation. Using different methods of analysis, each individual study illustrates environmental features were captured using FPs. However, FPs as a safety inventory tool for data collection are not free of problems. Some of the challenges relate to validity (content and criterion), in other words, the adequacy of CPTED principles applied to transit environments as well as among the different measures. Others are related to reliability or generalizability.

Overall, FPs are better suited for collecting on-site information for subway stations than for shopping centers or parks. Note, however, that these conclusions are dependent on the following three assumptions.

(1) The observer starts from similar theoretical principles of CPTED/environmental criminology and fear of crime when employing this protocol, which is not always the case. There might be variations in knowledge and experience with the tool or theories that are bound to affect what one sees in reality. On top of that, cultural differences in the way observers approach CPTED are bound to affect the use of

Table 4. Overall assessment of validity, reliability and generalizability of FPs applied to subway stations, shopping center and parks.

\begin{tabular}{|c|c|c|c|}
\hline & \multicolumn{3}{|c|}{ Environmental features collected using FPs* } \\
\hline & Subway stations & Shopping center & Parks \\
\hline Validity & $\begin{array}{l}\text { High } \\
\text { Medium }\end{array}$ & $\begin{array}{l}\text { Medium } \\
\text { Medium }\end{array}$ & $\begin{array}{l}\text { Medium/Low } \\
\text { Medium }\end{array}$ \\
\hline Reliability & $\begin{array}{l}\text { High/Medium } \\
\text { High } \\
\text { High }\end{array}$ & $\begin{array}{l}\text { High/Medium } \\
\text { High } \\
\text { Medium }\end{array}$ & $\begin{array}{l}\text { Medium/Low } \\
\text { Medium/Low } \\
\text { Medium }\end{array}$ \\
\hline Generalizability & $\begin{array}{l}\text { High/medium } \\
3 \text { High } \\
1 \text { Medium/High } \\
1 \text { Medium }\end{array}$ & $\begin{array}{l}\text { Medium } \\
4 \text { Medium } \\
1 \text { High } \\
1 \text { High/Medium }\end{array}$ & $\begin{array}{l}\text { Medium } \\
\mathbf{3} \text { Medium } \\
\mathbf{3} \text { Medium/Low }\end{array}$ \\
\hline
\end{tabular}

${ }^{a}$ For example, because of differences of the park environments, size and location, the internal reliability of FPs for parks was classified as medium/low while for FPs for stations, where the standardization of the stations facilitates internal reliability, the score assigned was high. 
FPs (as reference, see the previous discussion about territoriality, pointed out by Ekblom (2011)) and how the data collected on-site are interpreted as evidence.

(2) The evidence from the protocols is compared with other data sources, and among types of environment, as done in this study. This ensures a certain degree of validity of the evidence collected in the field.

(3) The relationship between safety and environment captured by the observer is dependent on city-country contexts as well as temporal variations at the time of data collection. Issues of generalizability have to be considered for each particular case. As previously discussed, generalizability is not always a desirable or relevant feature of research and should not be considered as the 'only' measure of the quality of FPs for data collection. Qualitative meta-synthesis (summarized qualitative findings from disparate studies into a single framework) should be encouraged (Finfgeld-Connett, 2010; Leung, 2015), since the search for generalizability from different types of studies and frameworks is fundamental to create a common base for practice and policy.

\section{Conclusions and recommendations}

The aim of this study was to report on the experiences of FPs as a guide for taking inventory of safety conditions in public places. By using validity, reliability, and generalizability criteria, we assessed how well these FPs worked for collecting data in subway stations, parks, and shopping centers. The article summarizes more than 10 years of the research in this field in Sweden and Lithuania, involving different observers using similar FPs. These protocols varied in the way they were employed in the field, from wellstructured checklists in subway stations, to a loose itinerary template employed in safety walks in parks. Although the inspection of an environment using protocols is not conclusive with regards as to whether the environment is the main cause of crime, this article provides some evidence as to how data gathered by these tools can help elucidate the links between crime and environment in a more systematic way. This also applies to the use of protocols to capture the relationship between environment and people's perceived safety.

This study also makes an important theoretical contribution to CPTED frameworks. It shows that in conjunction with data mapped using BIM diagrams and GIS, CPTED principles implemented in these FPs can provide a solid toolkit for inspecting safety conditions in public places. Further hypothesis testing with data from FPs can be executed using more structured ways of collecting data, as illustrated in Appendix. Data permitting, future research should devote time to test, in a more rigorous manner, the potential of FPs for data collection by better controlling content validity and reliability parameters (time and inter-user). This route of development requires improvements in this analytical model, as suggested by Ekblom (2011), improvements that demand an in-depth discussion of the basic constructs behind each element of CPTED before any fieldwork starts.

In particular, future research should devote time to improving inter-observer reliability of the data collected using the FPs. This means that different observers should show a capacity to identify (or perceive) similar evidence when assessing CPTED principles in a particular place. Issues of 'minimum agreeable knowledge' of the theoretical concepts 
among observers before starting the fieldwork would be desirable in future studies, not only related to crime (e.g. CPTED, situational crime prevention, routine activity) but also perceived safety (e.g. basic notions about environmental and personal triggers of fear).

This also involves a discussion of 'a minimum sample of observers' and 'group representativeness' (number of participants by type inspecting an area) taking part in the fieldwork before drawing conclusions about 'types of observer' and 'perceptions of safety' for a particular environment. For detection of problems with both crime and perception of safety, the use of grading and Likert scales as well as photographs and notes can facilitate and guide comparability between measures from different observers. Internet, mobile phones, and apps of all sorts should be further explored to facilitate data collection. Regardless of the method, pre-tests such as pilot studies using principles of research validity, reliability, and generalizability are encouraged before applying FPs in full as an inventory tool in a particular study.

Future studies using FPs should reflect upon the importance of conclusions drawn based on specific urban and rural contexts. The difference in nature and magnitude of security problems faced by cities of the Global South also demands a consideration of whether the available planning tools and theories are adequate for interpreting their critical problems. For instance, one wonders what CPTED means for architects and urban planners engaged in planning refugee camps, where women and children are often victims of sexual abuse. Similarly, practical challenges are also faced by safety experts performing fieldwork inspection in residential areas where walls are made of cardboard and streets lack asphalt and illumination.

This study shows evidence that FPs can be a valuable tool in planning because they can be used by a wide variety of groups of experts and in different circumstances and offer a wide range of benefits to participants from different backgrounds. However, as any other tool, they are not problem-free. Based on current evidence, FPs perform better in subway stations (albeit depending on the part of the station) than they do in shopping centers and parks. FPs, as part of safety walks in particular, have potential as suggested by Dymén and Ceccato (2012) to be a supportive tool for urban planners and safety experts to engage individuals to take action and 'correct' safety problems while contributing to citizens' empowerment.

\section{Disclosure statement}

No potential conflict of interest was reported by the author.

\section{Funding}

This work was supported by the Boverket National Board of Housing, Building and Planning [8061/ 2018].

\section{Notes on contributor}

Vania Ceccato is a Professor at the Department of Urban Planning and Environment, School of Architecture and the Built Environment, KTH Royal Institute of Technology, Stockholm, Sweden. She coordinates the national network Safeplaces (Säkraplatser). Ceccato is interested in the 
relationship between the built environment and safety, in particular, the space-time dynamics of crime and people's routine activity.

\section{References}

Armitage, R. (2013). Crime prevention through housing design: policy and practice. Basingstoke, UK: Palgrave Macmillan.

Armitage, R., Monchuk, L., \& Rogerson, M. (2011). It looks good, but what is it like to live there? Exploring the impact of innovative housing design on crime. European Journal on Criminal Policy and Research, 17, 29-54.

Bamzar, R. (2019). Assessing the quality of the indoor environment of senior housing for a better mobility: A Swedish case study. Journal of Housing and the Built Environment, 34(1), 23-60. doi:10.1007/s10901-018-9623-4.

Brantingham, P., \& Brantingham, P. (1995). Criminality of place: Crime generators and crime attractors. European Journal on Criminal Policy and Research, 3, 1-26.

Ceccato, V. (2013). Moving safely: Crime and perceived safety in Stockholm's subway stations. Plymouth: Lexington.

Ceccato, V. (2016). Public space and the situational conditions of crime and fear. International Criminal Justice Review, 26, 69-79.

Ceccato, V., Falk, Ö., Parsanezhad, P., \& Tarandi, V. (2018). Crime in a Scandinavian shopping centre. In A.R. Ceccato V. (Ed.), Retail crime: International evidence and prevention (pp. 179-213). Cham: Palgrave Macmillan.

Ceccato, V., \& Bamzar, R. (2016). Elderly victimization and fear of crime in public spaces. International Criminal Justice Review, 26, 115-133.

Ceccato, V., Haining, R., \& Signoretta, P. (2002). Exploring crime statistics in Stockholm using spatial analysis tools. Annals of the Association of American Geographers, 22, 29-51.

Ceccato, V., \& Lukyte, N. (2011). Safety and sustainability in a city in transition: The case of Vilnius, Lithuania. Cities, 28(1), 83-94. doi:10.1016/j.cities.2010.10.001

Ceccato, V., \& Hansson, M. (2013). Experiences from assessing safety in Vingis park, Vilnius, Lithuania. Review of European Studies, 5(5), 1-16.

Ceccato, V., \& Paz, Y. (2017). Crime in São Paulo's metro system: Sexual crimes against women. Crime Prevention and Community Safety, 19, 211-226.

Ceccato, V., \& Uittenbogaard, A.C. (2014). Space-time dynamics of crime in transport nodes. Annals of the Association of American Geographers, 104, 131-150.

Ceccato, V., Uittenbogaard, A.C., \& Bamzar, R. (2013). Safety in Stockholm's underground stations: The importance of environmental attributes and context. Security Journal, 26, 33-59.

Ceccato, V., Tcacencu, S. (2018). Perceived safety in a shopping centre: A Swedish case study. In V. C. A \& R. Armitage (Eds.), Retail crime (pp. 215-242). Cham: Palgrave Macmillan.

Clark, V., \& Creswell, J.W. (2011). Designing and conducting mixed methods research. Thou-sand Oaks, CA: Sage.

Clarke, R.V. (1983). Situational crime prevention: Its theoretical basis and practical scope. In M. M. Tonry, N (Ed.), Crime and justice: An annual review (pp. 225-256). Chicago: University of Chicago Press.

Clarke, R.V. (1997). Situational crime prevention: Successful case studies. New York, NY: Harrow \& Heston.

Clarke, R.V. (2012). The theory of crime prevention through environmental design. Rutgers University, NJ: CPTED.

Cohen, L.E., \& Felson, M. (1979). Social change and crime rate trends: A routine activity approach. American Sociological Review, 44, 588-608.

Cozens, P., \& Love, T. (2015). A review and current status of crime prevention through environmental design (CPTED). Journal of Planning Literature, 30, 393-412.

Cozens, P.M., Saville, G., \& Hillier, D. (2005). Crime prevention through environmental design (CPTED): A review and modern bibliography. Property Management, 23, 328-356. 
Creswell, J.W. (2013). Qualitative inquiry \& research design: Choosing among five approaches. Thousand Oaks, CA: Sage.

Crowe, T. (2000). Crime prevention through environmental design: Applications of architectural design and space management concepts. Oxford: Butterworth-Heinemann.

de Melo, S.N., Matias, L.F., \& Andresen, M.A. (2015). Crime concentrations and similarities in spatial crime patterns in a Brazilian context. Applied Geography, 62, 314-324.

DeKeseredy, W.S., Donnermeyer, J.F., \& Schwartz, M.D. (2009). Toward a gendered second generation CPTED for preventing woman abuse in rural communities. Security Journal, 22, 178-189.

Dymén, C., \& Ceccato, V. (2012). An international perspective of the gender dimension in planning for urban safety. In V. Ceccato (Ed.), The urban fabric of crime and fear (pp. 311-339). Netherlands: Springer.

Ekblom, P. (2011). Deconstructing CPTED... and reconstructing it for practice, knowledge management and research. European Journal on Criminal Policy and Research, 17, 7-28.

Ekblom, P. (2019). Sharpening up CPTED - Towards an ontology based on crime science and ecology. In P. Ekblom \& R. Armitage (Eds.), Rebuilding crime prevention through environmental design: Strengthening the links with crime science. (pp. 266). Abingdon, Oxon: Routledge.

Felson, M. (1995). Those who desincourage crime. In (Eds.), Crime and place (pp. 53-66). Monsey, NY: Criminal Justice Press.

Felson, M. (2002). Crime and everyday life. Thousand Oaks: Sage.

Finfgeld-Connett, D. (2010). Generalizability and transferability of meta-synthesis research findings. Journal of Advanced Nursing, 66, 246-254.

Grönlund, B. (2012). Is hammarby sjöstad a model case? Crime prevention through environmental design in Stockholm, Sweden. In V. Ceccato (Ed.), The urban fabric of crime and fear (pp. 283-310). Netherlands: Springer.

lqbal, A., \& Ceccato, V. (2016). Is CPTED useful to guide the inventory of safety in parks? A study case in Stockholm, Sweden. International Criminal Justice Review, 26, 150-168.

Jacobs, J. (1961). The death and life of great American cities. New York: Vintage Books.

Jeffery, C.R. (1977). Crime prevention through environmental design. Beverly Hills: Sage.

Kajalo, S., \& Lindblom, A. (2010). The perceived effectiveness of surveillance in reducing crime at shopping centers in Finland. Property Management, 28, 47-59.

Kelley, T.L. (1972). Interpretation of educational measurements. New York: Macmillan.

Leung, L. (2015). Validity, reliability, and generalizability in qualitative research. Journal of Family Medicine and Primary Care, 4, 324-327.

Lindblom, A., \& Kajalo, S. (2011). The use and effectiveness of formal and informal surveillance in reducing shoplifting: A survey in Sweden, Norway and Finland. The International Review of Retail, Distribution and Consumer Research, 21, 111-128.

Loukaitou-Sideris, A. (2012). Safe on the move: The importance of the built environment. In V. Ceccato (Ed.), The urban fabric of crime and fear (pp. 85-110). Netherlands: Springer.

Németh, J. (2012) Controlling the commons: How public is public space? Urban Affairs Review.

Newman, O. (1972). Defensible space - Crime prevention through urban design. New York: Collier Books.

Pain, R. (2000). Place, social relations and the fear of crime: A review. Progress in Human Geography, 24, 365-387.

Reynald, D.M., \& Elffers, H. (2009). The future of Newman's defensible space theory: Linking defensible space and the routine activities of place. European Journal of Criminology, 6, 25-46.

Rhodes, W., \& Conly, C. (1981). Crime and mobility: An empirical study. In P.J. Brantingham \& P. L. Brantingham (Eds.), Environmental criminology (pp. 167-188). Beverly Hills; Canada: Sage.

Saville, G. 2013. Third generation of CPTED. www.alternation.ca.

Saville, G. (2018). SafeGrowth: Building neighborhoods of safety \& livability 230. Charleston: CreateSpace.

Saville, G., \& Clear, T. (2000). Community renaissance with community justice. The Neighborworks Journal, 18, 18-24. 
Shaftoe, H., \& Read, T. (2005). Planning out crime: The appliance of science or an act of faith?. In N. Tilley (Ed.), Handbook of crime prevention and community safety (pp. 245-265). Devon, UK: Willan Publishing.

Sutton, A., Cherney, A., \& White, R. (2008). Evaluating crime prevention. Melbourne: Cambridge University Press.

Weisburd, D., Morris, N., \& Groff, E. (2009). Hot spots of juvenile crime: A longitudinal study of arrest incidents at street segments in Seattle, Washington. Journal of Quantitative Criminology, $25,443-467$.

Wikström, P.-O.H., \& Treiber, K. (2017). Beyond risk factors: an analytical approach to crime prevention. In B. Teasdale \& M.S. Bradley (Eds.), Preventing crime and violence (pp. 73-87). Cham: Springer International Publishing.

Wikström, P.-O.H., Mann, R.P., \& Hardie, B. (2018). Young people's differential vulnerability to criminogenic exposure: Bridging the gap between people- and place-oriented approaches in the study of crime causation. European Journal of Criminology, 15, 10-31.

\section{Appendix - Example of fieldwork protocol: Stockholm's subway stations}

Idstation = Station's ID, Station name, Station code, Characteristics of the station's platform (horizontal) and Selection of stations by line Red, Blue and Green (vertical).

Example of variables*

\begin{tabular}{|c|c|c|c|c|c|c|c|c|c|}
\hline Idstation & Station name & Station code & PVis & Pillu & Pcorn & Phide & Psun & Ploun & PSur \\
\hline 1 & T Centralen & T_1 & $M$ & $y$ & $n$ & $y$ & $n$ & $n$ & $M$ \\
\hline 2 & T Centralen & T_2 & $\mathrm{H}$ & $y$ & $\mathrm{n}$ & $n$ & $\mathrm{n}$ & $\mathrm{n}$ & $\mathrm{H}$ \\
\hline 3 & T Centralen & T_3 & $\mathrm{H}$ & $y$ & $y$ & $\mathrm{n}$ & $\mathrm{n}$ & $\mathrm{n}$ & $M$ \\
\hline 4 & Slussen & Slu & M & $y$ & $\mathrm{n}$ & $y$ & $\mathrm{n}$ & $\mathrm{n}$ & $\mathrm{L}$ \\
\hline 5 & Gamla Stan & GaS & M & $y$ & $\mathrm{n}$ & $y$ & $\mathrm{n}$ & $\mathrm{n}$ & $\mathrm{L}$ \\
\hline 6 & Fridhemsplan & F_B & M & $y$ & $y$ & $y$ & $\mathrm{n}$ & $\mathrm{n}$ & M \\
\hline 7 & Fridhemsplan & F_G & M & $y$ & $y$ & $y$ & $n$ & $\mathrm{n}$ & $\mathrm{L}$ \\
\hline 8 & Hjulsta & $\mathrm{Hju}$ & $\mathrm{H}$ & $y$ & $n$ & $y$ & $\mathrm{n}$ & $\mathrm{n}$ & $\mathrm{H}$ \\
\hline 9 & Akalla & Aka & $\mathrm{H}$ & $y$ & $\mathrm{n}$ & $y$ & $\mathrm{n}$ & $\mathrm{n}$ & M \\
\hline 10 & Tensta & Ten & M & $y$ & $\mathrm{n}$ & $y$ & $n$ & $\mathrm{n}$ & M \\
\hline 11 & Husby & Hub & $\mathrm{H}$ & $y$ & $\mathrm{n}$ & $y$ & $\mathrm{n}$ & $\mathrm{n}$ & M \\
\hline 12 & Rinkeby & Rib & M & $y$ & $y$ & $y$ & $\mathrm{n}$ & $\mathrm{n}$ & M \\
\hline 13 & Kista & Kis & M & $y$ & $\mathrm{n}$ & $y$ & $y$ & y & M \\
\hline 14 & Rissne & Ris & $\mathrm{H}$ & $y$ & $\mathrm{n}$ & $n$ & $n$ & $\mathrm{n}$ & $\mathrm{H}$ \\
\hline 15 & Hallonbergen & $\mathrm{Hab}$ & $\mathrm{H}$ & $y$ & $\mathrm{n}$ & $y$ & $\mathrm{n}$ & $\mathrm{n}$ & M \\
\hline 16 & Duvbo & Duv & $\mathrm{H}$ & $y$ & $\mathrm{n}$ & $\mathrm{n}$ & $\mathrm{n}$ & $n$ & $\mathrm{H}$ \\
\hline 17 & Näckrosen & När & $\mathrm{H}$ & $y$ & $\mathrm{n}$ & $y$ & $\mathrm{n}$ & $\mathrm{n}$ & M \\
\hline 18 & Sundbyberg Centrum & Sbg & M & $y$ & $y$ & $y$ & $\mathrm{n}$ & $\mathrm{n}$ & $\mathrm{L}$ \\
\hline 19 & Vreten & Vre & M & $y$ & $\mathrm{n}$ & $y$ & $n$ & $\mathrm{n}$ & $\bar{M}$ \\
\hline 20 & Huvudsta & Huv & $\mathrm{H}$ & $y$ & $\mathrm{n}$ & $n$ & $\mathrm{n}$ & $\mathrm{n}$ & $\mathrm{H}$ \\
\hline 21 & Solna Centrum & SoC & $\mathrm{H}$ & $y$ & $\mathrm{n}$ & $y$ & $\mathrm{n}$ & $\mathrm{n}$ & $M$ \\
\hline 22 & Västra Skogen & VäS & M & $y$ & $y$ & $y$ & $n$ & $\mathrm{n}$ & $M$ \\
\hline 23 & Stadshagen & Sha & $\mathrm{H}$ & $y$ & $y$ & y & $\mathrm{n}$ & $\mathrm{n}$ & $M$ \\
\hline 24 & Rådhuset & Råd & $\mathrm{H}$ & $y$ & $y$ & $y$ & $\mathrm{n}$ & $\mathrm{n}$ & $\mathrm{L}$ \\
\hline 25 & Kungsträdgården & $\mathrm{Ktg}$ & M & $y$ & $y$ & $y$ & $n$ & $\mathrm{n}$ & $\mathrm{L}$ \\
\hline 26 & Hässelby Strand & HäS & M & $y$ & $n$ & $n$ & $y$ & $\mathrm{n}$ & $\mathrm{H}$ \\
\hline 27 & Hässelby Gård & HäG & $\mathrm{H}$ & $y$ & $\mathrm{n}$ & $y$ & $y$ & $\mathrm{n}$ & $\mathrm{H}$ \\
\hline 28 & Johannelund & Jol & $\mathrm{H}$ & $y$ & $\mathrm{n}$ & $\mathrm{n}$ & $y$ & $\mathrm{n}$ & $\mathrm{L}$ \\
\hline 29 & Vällingby & Vby & M & $\mathrm{n}$ & $y$ & $n$ & $\mathrm{n}$ & $\mathrm{n}$ & $M$ \\
\hline 30 & Råcksta & Råc & $\mathrm{H}$ & $y$ & $\mathrm{n}$ & $y$ & $y$ & $\mathrm{n}$ & $M$ \\
\hline
\end{tabular}




\begin{tabular}{llc}
\hline PVis & \multicolumn{1}{c}{ Platform - high visibility } & H/M/L \\
\hline Pillu & Platform - sufficient/effective illumination & Y/N \\
Pcorn & Platform - dark corners & Y/N \\
Phide & Platform - hiding places & Y/N \\
Psun & Platform - sun light easily illumantes the covered places & Y/N \\
Ploun & Platform - lounge is easily visible & Y/N \\
PSur & Platform -high potential surveillance & $H / M / L$ \\
\hline
\end{tabular}

aNote that variables were whenever possible collected for all sections of the stations: platform, lounges, transition area, exits and immediate surroundings.

Example of variables - Pvis $=$ Visibility at platform; Pillu = Illumination conditions at platform; Pcorn $=$ Presence of dark corners at platforms; Phide $=$ Hiding places at platform; PSun $=$ Sunlight easily illuminates platform; PLoun $=$ Platform visibility towards lounge area; PSur = Possibility of surveillance by others at platform. 